\title{
Supporting transition toward conservation agriculture: a framework to analyze the learning processes of farmers
}

\author{
Hélène CRISTOFARI ${ }^{1,2}$, NATHAlie GIRARD $^{1}$ and DanièLe MAGDA ${ }^{1}$
}

\begin{abstract}
Conservation agriculture (CA) is based on 3 principles, namely reduced soil disturbance, permanent soil cover, and more complex and legume-rich rotations; and multiple studies have shown its positive impacts. Because CA relies on a variety of ecological processes, it is more deeply rooted in a specific ecological context than conventional agriculture. The complexity of these processes makes it difficult to elaborate general recipes to be applied by farmers, who therefore need to learn to make their own choices adapted to their own agroecosystem. Consequently, helping farmers to move toward CA requires supporting them in learning to develop their own practices. Farmers' learning remains poorly investigated at the individual level, with in particular very little work focusing on learning in CA. We hypothesize that the processes involved in learning to practice CA may differ from those involved in conventional agriculture: for instance, the current lack of detailed reference documents may induce farmers to experiment more. Against this background, we here aimed at describing how farmers experienced in CA learn, by qualifying their learning mechanisms and processes. To do so, we conducted five comprehensive interviews with farmers experienced in CA, and then inductively analyzed the data to explore the diversity of learning mechanisms involved, i.e. the elementary actions or cognitive activities which, organized together, constitute a learning process. We, thus, propose a descriptive framework of non-ordered and non-obligatory learning mechanisms that appear to be mobilized by farmers experienced in conservation agriculture, as a first step toward a deeper analysis of their learning processes. We further emphasize the often unintentional aspect of learning, as well as the importance, for farmers who wish to implement CA practices, of developing new standards of comparison. A better understanding of these learning processes would help improving extension services and training for farmers.
\end{abstract}

Keywords: agroecology, conservation agriculture, farmers' learning, learning mechanism, learning process, qualitative analysis, inductive approach

\section{Introduction}

\section{Conservation agriculture as a promising agroecological approach}

Conservation agriculture is classically defined today as a set of practices respecting three main principles, namely reduction of soil disturbance, permanent soil cover, and diversification of the crop rotation (FAO 2012); a fourth principle, related to the integrated management of weeds, has also been suggested (FArooQ, M. and Siddique, K.H.M. 2015). These principles, taken together, pri- marily aim at reducing soil erosion: this was in fact the main goal pursued when such practices became popular in North America in the 1930s, following the ecological and social catastrophe of the Dust Bowl in the American Mid-West.

However, a number of additional benefits have also been largely suggested or demonstrated, including an increase in soil water retention, a reduced need for mineral fertilization, the enhancement of biodiversity and so on (Hobbs, P.R. et al. 2008; Dordas, C. 2015; Nawaz, A. and Ahmad, J.N. 2015). It is important to note that such advantages may be at-

\footnotetext{
${ }^{1}$ AGIR, Université de Toulouse, INRA (French National Institute for Agricultural Research), INPT, INP-EI PURPAN, Castanet-Tolosan, France. E-mail: helene.cristofari@toulouse.inra.fr. Corresponding author.

${ }^{2}$ Université Toulouse III Paul Sabatier, Toulouse, France.
} 
tained - at different degrees - through a diversity of practices: following the three main principles may, thus, encompass different levels of soil disturbance, from "zero disturbance" to strip-till or a very shallow tillage, different choices of cover crops and cover crop management, more or less diversified rotations.

These practices tend to share a common characteristic: they are mostly based on the management of ecological processes to replace technological inputs. For instance, the introduction of sorghum in the crop rotation results in a partial compensation of the absence of tillage by the fissuring effect of the sorghum deep taproots. Consequently, conservation agriculture practices can be considered as agroecological practices, in the sense of practices based on the management of ecological processes.

\section{An adoption still limited in Europe}

Despite the manifold advantages brought to farmers and society as a whole by conservation agriculture practices, their adoption remains somehow limited in Europe, with wide differences between countries. Diverse possible explanations have been put forward, at the political, economic and cognitive levels. BAsCH, G. et al. (2015) underline the important role of the Common Agricultural Policy (CAP) in this matter: they argue that because of a historical orientation of the CAP toward high yields, farmers tend to think more in terms of maximizing their yields and the subsequent subsidies, rather than reducing their production costs or investing in long-term soil amelioration.

It has also been suggested that conservation agriculture is difficult to adopt because of its "knowledge-intensive" character (FrIEDRICH, T. et al. 2009; INGRAM, J. 2010): it relies on ecological processes that are only very partially known, and very specific to a particular place (Lahmar, R. 2010; De Tourdonnet, S. et al. 2013). Farmers, thus, need to change the way they make their daily decisions, and the objects they observe to found such decisions (DE Tourdonnet, S. et al. 2013). Consequently, a better understanding of the way farmers learn may help mitigate such a cognitive issue.

\section{Farmers' learning: overview and missing aspect}

A number of authors have studied how farmers learn, but usually focusing on specific situations where learning occurs. For instance, some studies explored the learning situations involving an "expert", such as a more experienced farmer or a technician (LABARTHE, P. 2009), while other works concentrate on the transmission of knowledge between newcomers and more experienced farmers (McGreevy, S.R. 2012; Chrétien, F. 2013). Some authors examined learning situations involving knowledge exchange groups: building on two case-studies of Australian breeders, Millar, J. and Curtis, A. (1997), thus, suggested that farmers may undervalue their own knowledge, and that exchange among peers may help them get aware of their own knowledge, as well as facilitate the construction of common understandings between farmers and scientists.

Others focused on the origin of the information used: Kilpatrick, S. and Johns, S. (2003), thus, proposed a typology of farmers according to the learning sources they mobilize (extension agents, peers, single individuals or a diversity of persons). Finally, a growing body of studies explores the modalities and consequences of farmers' experiments (e.g. Kummer, S. et al. 2012; VogL, C.R. et al. 2015).

However, fewer works deal with farmers' learning in a more comprehensive way, as a process encompassing a diversity of such specific learning situations. Some efforts were made in this direction by authors such as Lyon, F. (1996), who described diverse aspect of the learning processes of British farmers, without a specific focus on a certain learning situation. More recently, Chantre, E. et al. (2014) proposed 10 learning styles defined by the learning source used and/or typical action (e.g. "Autonomous testing of an idea coming from an extension agent") undertaken by farmers reducing their chemical inputs doses. 
Such studies shed light on the way farmers learn, but they are not concerned with complex agroecological practices such as conservation agriculture: thus, the question remains of how farmers learn to develop these practices based on the management of ecological processes, in the absence of exhaustive technical references. Moreover, it is noticeable that quite a few authors (Table 1) interested in farmers' learning processes usually base their analysis on rather convergent views of learning: they tend to consider it as an intentional process based on problem resolution and occurring through roughly similar steps, namely defining a problem, conceiving a solution, testing the solution, monitor the outcome and decide if the solution is adequate or not.

We thought that such a view of learning may be relevant mostly for farmers who are intentionally trying implement a specific change of practices (such as reducing synthetic fertilizers doses, for instance). However, in the case of farmers who are learning to practice conservation agriculture, there is not one single clear-cut change of practice: quite the contrary, switching to this type of agriculture requires an evolution of the whole system, as well as a deep change in the way the system is perceived (Ingram, J. 2010; De Tourdonnet, S. et al. 2013). Furthermore, learning does not necessarily result from the intentional resolution of problems, it may also happen as a consequence of a surprise, an unexpected outcome (Lyon, F. 1996; DARnhofer, I. et al. 2010). As a result, it is possible that such a representation of learning, organized in ordered steps starting from a problem to be solved, may not be the most accurate one for farmers experienced in conservation agriculture.

\section{Our research goal}

In this study, we therefore adopt an inductive approach to see how farmers' learning may be described. To do so, we here explore the diversity of learning mechanisms involved - i.e. the elementary actions or cognitive activities which, organized together, constitute a learning process - with an aim at proposing a descriptive framework of the learning mechanisms that appear to be mobilized by farmers experienced in conservation agriculture, as a first step toward a deeper analysis of their learning processes.

\section{Method}

\section{Study area: South-Western France}

We focused on a region located in SouthWestern France (roughly between the cities of Toulouse and Carcassonne), because it presents several issues which make the implementation of conservation agriculture

Table 1. Example of sequences of learning steps for farmers*

\begin{tabular}{|c|c|}
\hline Steps of learning & Authors \\
\hline $\begin{array}{l}\text { - Expectation } \\
\text { - Planning } \\
\text { - Scale } \\
\text { - Observation } \\
\text { - Repetition } \\
\text { - Documentation }\end{array}$ & Leitgeb, F. et al. 2014 \\
\hline $\begin{array}{l}\text { - Warning sign stage } \\
\text { - Experimenting stage } \\
\text { - Evaluation stage }\end{array}$ & Chantre, E. et al. 2015 \\
\hline $\begin{array}{l}\text { - Choice of a technique, decision to apply it and preparation for the imple- } \\
\text { mentation. } \\
\text { - Several tests and errors, adaptation of specific monitoring and operational } \\
\text { methods, amplification. } \\
\text { - Evaluation of consequences of new practices on the cropping system. }\end{array}$ & Toffolini, Q. 2016 \\
\hline
\end{tabular}

${ }^{*}$ According to recent studies. 
especially interesting. Soil erosion is particularly high in this area, causing regular problems to both farmers and other citizens (e.g. loss of fertile soil, mudslides); moreover, the warm summers occasion frequent drought periods. Finally, it has been suggested that the past crops, such as the widespread culture of vine, has led in different places to an important reduction in soil organic content. Accordingly, the potential benefits of conservation agriculture in terms of reduction of soil erosion, enhancement of water retention and increase in soil organic matter would be especially promising in that region.

\section{Sample of learning mechanism}

Our study is based on 5 in-depth qualitative case studies of farmers experienced in conservation agriculture practices. We chose farmers based on two sets of criteria.

- First, they had to be sufficiently experienced: we considered that this was the case when they had been implementing the three principles of conservation agriculture for at least 10 years: it has been shown (Piтtelkow, C.M. et al. 2015) that switching to conservation agriculture leads to a yield decline during the first few years after starting their transition, and that the yields increase again, back to the initial level or sometimes higher, over the later years. As a result, choosing farmers with at least 10 years of experience enabled us to select people who had some hindsight on the whole transition, and who learned to overcome the more difficult moments. Moreover, the 5 farmers selected were recognized by their peers as particularly advanced in conservation agriculture practices.

- Second, since our aim was the construction of a framework to describe the diversity of learning mechanisms, we had to select $a$ sample of learning mechanisms as diverse as possible. It has been suggested that the way we learn depends on different factors, such as individual personality (KoLB, D.A. 1984), the object of learning - "what we learn about"or the learning situation (CHANTRE, E. and
Cardona, A. 2014). Consequently, we selected our sample according to the theoretical sampling strategy (EISENHARDT, K.M. 1989), trying to include diversity for all these factors. Practically speaking, this means that the selected farmers were characterized by a diversity of professional paths (more or less academic education, different family ties to agriculture), a diversity of relationships with other farmers and with extension agents, a diversity of productions (arable crops alone, with vines, with livestock), and a diversity of current conservation agriculture practices (from direct seeding to shallow tillage, different ways to manage cover crops, varied uses of chemical inputs...).

\section{Qualitative data collection through} comprehensive interviews

Our qualitative data was gathered through comprehensive interviews, i.e. a type of interview which leaves the informants ample room to develop their ideas and follow their own line of thought from one topic to another, while the interviewer only gives some prompting to re-launch the discourse and go deeper in details, or refocus the speech around the main topics of the interview, here exposed in Table 2. Our interviews lasted for a total duration of 11 hours and 30 minutes.

\section{Inductive data structuring}

The interviews were then integrally transcribed and we structured the resulting scripts using the Nvivo qualitative analysis software. Taking one interview after the other, in random order, we coded the learning mechanisms in the inductive way characteristic of conventional coding (Hsien, H.E. and Shannon, S.E. 2005). Consequently, there was no previously defined list of nodes to be used. Each time the interviewee talked about how he learned something, we coded this excerpt of the text with a short expression describing "how the farmer learned". 
Table 2. Comprehensive interview grid to analyze the learning processes of farmers experienced in conservation agriculture

\begin{tabular}{|c|c|c|}
\hline & \multicolumn{2}{|c|}{ General information } \\
\hline $\mathrm{I}$ & \multicolumn{2}{|c|}{$\begin{array}{l}\text { Surface? Soil type(s)? Irrigation? } \\
\text { How long have you been working on this farm? Is it a family heritage? Other family links to agriculture? } \\
\text { Initial training? Have you had any other profession? How long have you been a farmer? } \\
\text { Since you started farming, which productions have you had? }\end{array}$} \\
\hline \multirow[b]{2}{*}{ II } & Technical themes & Types of questions \\
\hline & $\begin{array}{l}\text { Crop choices/rotation } \\
\text { Soil management (including soil erosion) } \\
\text { Cover crops } \\
\text { Weeds } \\
\text { Pests } \\
\text { Choices of varieties/seed production }\end{array}$ & $\begin{array}{l}\text { What are your current practices? } \\
\text { How long has it been so? } \\
\text { What did you do before? } \\
\text { Why were such changes implemented? } \\
\text { How were such changes implemented? } \\
\text { Where did you get the idea from? } \\
\text { How did you judge if the practice was satisfactory? } \\
\text { Are you considering any other change now? }\end{array}$ \\
\hline & \multicolumn{2}{|c|}{ If not alluded to before } \\
\hline III & \multicolumn{2}{|c|}{$\begin{array}{l}\text { Relationships with peers (either in conservation agriculture or not, neighbours or farther away, casu- } \\
\text { ally or through networks, associations...). } \\
\text { Relationships with extension agents. } \\
\text { Relationships with researchers. }\end{array}$} \\
\hline
\end{tabular}

We used words that were as close as possible to the farmer's, while also trying to choose an expression not too specific to one particular excerpt, so that it could be re-used to code other parts of interviews dealing with the same mechanism. In the end, twelve different nodes were created (such as "Monitor the system", "Analyze the information acquired during monitoring"...), and 169 excerpts, ranging from a few words to several paragraphs, were coded with these nodes: these 169 excerpts constitute our total sample of learning mechanisms. We observed that saturation (or the absence of apparition of any new learning mechanism) was reached around the end of the fourth interview, thus, confirming the adequacy of our sample.

\section{Data analysis}

The data, thus, structured into smaller units through coding was then analyzed following a strategy close to the grounded theory construction (Glaser, B.G. and Strauss, A.L. 2009). As a first step, we went through all excerpts coded with each node, and organized them in hierarchical categories. We then identified possible links between the twelve hierarchical systems of categories obtained, and merged part of them, thus, building the grid of learning mechanisms presented hereafter. Because the categories of learning mechanisms had to be sufficiently general to include elements of discourse from different farmers, we could not strictly keep the words used by interviewee: consequently, the labels of the categories mechanisms of learning exposed in our results are often our own scientific terms, chosen because they were large enough to encompass the diverse specific expressions used by different farmers.

\section{Results}

A grid to describe the diversity of learning mechanisms

We organized the learning mechanisms emerging from our interviews into five categories corresponding to different steps in the learning process (Table 3 ) these possible steps are not always present for each farmer, nor do they represent a logical sequence which is necessarily followed. They are merely larger cat- 
Table 3. Learning mechanisms of farmers experienced in conservation agriculture*

\begin{tabular}{|c|c|c|c|}
\hline \multirow{2}{*}{ Learning steps } & \multicolumn{3}{|c|}{ Learning sources } \\
\hline & Personal experience & Peers' inputs & Scientific inputs \\
\hline $\begin{array}{l}\text { Get an idea } \\
\text { of a new } \\
\text { practice. }\end{array}$ & $\begin{array}{l}\text { Conceive a new possible } \\
\text { practice. }\end{array}$ & $\begin{array}{l}\text { Find an idea of a new prac- } \\
\text { tice together with peers. } \\
\text { Imagine a new practice, by } \\
\text { getting inspiration from } \\
\text { peers' practices. }\end{array}$ & $\begin{array}{l}\text { Find an idea of a new prac- } \\
\text { tice from a scientific source. } \\
\text { Imagine a new practice, } \\
\text { based on a similar phenome- } \\
\text { non scientifically understood. }\end{array}$ \\
\hline \multirow{4}{*}{$\begin{array}{l}\text { Implement a } \\
\text { new practice. }\end{array}$} & \multicolumn{3}{|c|}{$\begin{array}{l}\text { Choose a time scale. } \\
\text { Choose a spatial scale. } \\
\text { Choose a degree of intensity of change. }\end{array}$} \\
\hline & \multicolumn{3}{|c|}{$\begin{array}{l}\text { Experiment in a planned way. } \\
\text { Experiment in an opportunistic way. }\end{array}$} \\
\hline & \multicolumn{2}{|c|}{ Experiment in a fortuitous way. } & \multirow[b]{2}{*}{$\begin{array}{l}\text { Rely on scientific methods } \\
\text { to conceive an experimental } \\
\text { design. }\end{array}$} \\
\hline & $\begin{array}{l}\text { Implement a new practice } \\
\text { individually. }\end{array}$ & $\begin{array}{l}\text { Implement a new practice } \\
\text { collectively. }\end{array}$ & \\
\hline
\end{tabular}

Monitor the system in a quantitative or qualitative way.

Monitor a specific experiment, or monitor the system in a more general way.

Monitoring

Choose a frequency and spatial scale for monitoring activities.

the state of the system.

Find indicators for the information desired.

Analyze the information obtained through monitoring in a more or less formal, quantitative way.

Choose a time and spatial scale for analyzing the information obtained through monitoring. Take into account independent variables.

\begin{tabular}{|c|c|c|c|}
\hline \multirow[b]{2}{*}{$\begin{array}{l}\text { Develop } \\
\text { standards of } \\
\text { comparison. }\end{array}$} & \\
\hline & Reject peers' standards. & $\begin{array}{l}\text { Compare one's system } \\
\text { with peers' systems. } \\
\text { Construct and share com- } \\
\text { mon ideals. }\end{array}$ & $\begin{array}{l}\text { Judge the state of the system } \\
\text { with respect to scientific } \\
\text { standards. }\end{array}$ \\
\hline \multirow{6}{*}{$\begin{array}{l}\text { Construct a } \\
\text { principle of } \\
\text { action. }\end{array}$} & $\begin{array}{l}\text { Confirm or disprove } \\
\text { information coming from a } \\
\text { scientific source. }\end{array}$ & $\begin{array}{l}\text { Confirm or disprove } \\
\text { information coming from a } \\
\text { personal observation. }\end{array}$ & $\begin{array}{l}\text { Confirm or disprove } \\
\text { information coming from a } \\
\text { personal observation. }\end{array}$ \\
\hline & $\begin{array}{l}\text { Confirm or disprove infor- } \\
\text { mation coming from peers. }\end{array}$ & $\begin{array}{l}\text { Confirm or disprove } \\
\text { information coming from a } \\
\text { scientific source. }\end{array}$ & $\begin{array}{l}\text { Confirm or disprove infor- } \\
\text { mation coming from peers. }\end{array}$ \\
\hline & $\begin{array}{l}\text { Put together different } \\
\text { personal experiences. }\end{array}$ & $\begin{array}{l}\text { Put together different } \\
\text { opinions from peers. }\end{array}$ & $\begin{array}{l}\text { Put together different scien- } \\
\text { tific sources. }\end{array}$ \\
\hline & & $\begin{array}{l}\text { Find among peers a direct } \\
\text { explanation for an ob- } \\
\text { served phenomenon. }\end{array}$ & $\begin{array}{l}\text { Find in a scientific source } \\
\text { a direct explanation for an } \\
\text { observed phenomenon. }\end{array}$ \\
\hline & & $\begin{array}{l}\text { Elaborate an explanation } \\
\text { of a phenomenon based } \\
\text { on an analogy with an } \\
\text { explanation of a similar } \\
\text { phenomenon heard from } \\
\text { peers. }\end{array}$ & $\begin{array}{l}\text { Elaborate an explanation } \\
\text { of a phenomenon based on } \\
\text { an analogy with a scientific } \\
\text { explanation of a similar phe- } \\
\text { nomenon. }\end{array}$ \\
\hline & & $\begin{array}{l}\text { Take a piece of information } \\
\text { coming from a peer as true } \\
\text { without further inquiry, } \\
\text { based on credit given to } \\
\text { this peer. }\end{array}$ & $\begin{array}{l}\text { Take a piece of information } \\
\text { coming from a scientific } \\
\text { source as true without fur- } \\
\text { ther inquiry, based on credit } \\
\text { given to this source. }\end{array}$ \\
\hline
\end{tabular}

* The left-side column indicates the main possible steps of the learning process, and the upper line presents the different sources that a farmer may mobilize when going through these different steps. 
egories which we defined, based on our data, to cluster more specific learning mechanisms.

Get an idea of a new practice. This may happen on one's own, or it may result from exchanges with peers, either directly (i.e. getting the idea from another farmer) or indirectly (i.e. on the basis of exchanges with peers, geting inspiration to personally conceive a new practice). For instance, this farmer directly used the idea of simplified sowing coming from a peer, but he adapted the idea of the observed crop rotation:

\footnotetext{
"For two years, we watched him do that...he'd sow, and it would work! And so yeah, we talked with him. From the start, he did a four-year rotation. So he had: wheat, sunflower, pea, rape. A wheat every four years, and he turned like that. And for us, we tried to do wheat-sunflower, wheat-soy, wheat-stuff..."
}

It may also come from scientific sources, this time again, directly or indirectly.

Implement a new practice. Farmers talked about implementing new practices at a variety of spatial scales (for instance, trying a cover crop on a smaller area first, or on a whole field at once) and time scales (e.g. trying direct seeding of corn just one year, or try it over several years to see whether the specific climatic conditions of the first year made a difference or not). New practices may also be implemented more or less progressively: some farmers try stopping tillage altogether, whereas others go through gradual change, from a $50 \mathrm{~cm}$ ploughing to $30 \mathrm{~cm}, 15 \mathrm{~cm}$ and so on, assessing the results as they proceed.

A farmer may implement a new practice in a more or less planned way, and we here suggest to distinguish three types of experiments: planned experiments, that are willingly foreseen and conducted by a farmer, opportunistic experiments, that happen when some mishap puts a farmer in an unexpected situation, prompting him to try something new which he would not otherwise have tried, and fortuitous experiments, that are not decided by a farmer but happen anyway. For instance, when a mistake or unforeseen climatic event leads to interesting results (because this last category is wholly unplanned, it can happen simultaneously to a group of peers, but it cannot include any scientific input, hence the exclusion of the "scientific inputs" column in Table 3). A case of opportunistic experiment was narrated by this farmer, who tried simplified sowing for the first time because of a machine breakdown:

"And so, it took the plough to break down, in 1992. It was broken. So, we needed two days to repair it, to get the parts. And the weather was not propitious. I finished sowing with a cultivator, and actually, when I saw the results, the wheat, it made no difference."

A farmer may implement a new practice on his own, but exchanges with peers may also affect how he decides to go about experimenting. Scientific documents or extension agents may also provide methodological inputs to plan an experimental design. It was for example the case for this farmer, who set up a complete scientific design:

"This year, I tried localized fertilization on soy (...). So, trials with liquid fertilizers, solid fertilizers formulas and mycorrhiza. There were six treatments, I believe ... six treatments, four control plots, and that's it!"

Monitor the state of the system. It includes two aspects: the acquisition of information about the system, and the subsequent analysis of such information. Farmers may acquire information about their system or parts of it in a qualitative or quantitative way, at different frequencies and spatial scales, with a variety of indicators (coming from scientific sources, co-developed with peers, and/or personally developed). The analysis of such information may also be more or less formal (from a very rough guess to a computer-aided statistical analysis including a diversity of independent variables). A mere observation of a change in colour can provide evidence for the farmer that his practices are being successful, as was the case for this farmer who saw his soil darken because of the increase of organic matter due to conservation agriculture practices:

"It isn't the compost that blackens the soil. But I see, each time the neighbouring ploughs, and it gets dry after, in my place the soil is much more coloured." 
This monitoring activity can apply either to a specific change of practice, or more broadly to the evolution of the system. It may be conducted in relation to several changes of practices (for instance, the effect of a simultaneous reduction of tillage and implementation on cover crops on soil erosion), or in relation to no conscious, planned change in practice, but a simple overall acquisition of information about the evolution of the system.

Construct standards of comparison. Farmers form an idea of what their system - or parts of it - should be like and what its performances should be. This can be based on exchanges with peers leading to the construction of a common ideal, on comparisons with other farmers' systems, or it can be inspired by scientific standards. Developing new standards seems to be particularly important for practicing conservation agriculture, as illustrated by a farmer who satirically talked about the idea of a "beautiful" soil for those who do not take into account the importance of soil life and organic matter:

"So you took out all weeds, your soil is moon-like it is like flour...It's wonderful! It's beautiful! There isn't one single plant! (...) So every year in winter you add 500 to $1,000 \mathrm{~kg}$ of organic matter granules that you buy at the cooperative because your soil actually lacks organic matter..."

Construct a principle of action. Farmers may construct a general principle of action based on different factors: for instance, they expressed to different degrees their needs to understand the cause of an observed phenomenon in order to consider it as generally true. Such an explanation may come directly from peers or scientific sources, or be more indirectly inspired from such sources. A farmer, thus, described how his crop rotation was based on his understanding of the ecological mechanisms at work:

\footnotetext{
"Sorghum has a very efficient root system, (...) it explores the soil, it pumps everything that's available. Which is another advantage for growing peas after that, in my opinion. Because the peas don't find any nitrogen leftover, they have to install the symbiosis to be able to develop. (...) I found elements that go in this direction in the literature. But it's not validated."
}

The different learning sources

We chose to organize the diversity of learning mechanisms identified in our data according to two dimensions that appeared important, the sources mobilized by farmers to learn, and the main learning steps. Obviously, the three sources of learning (personal experience, peers' input and scientific inputs) are to be seen as widely overlapping, rather than distinct categories: for instance, knowledge exchanges among farmers often include scientific information. However, distinguishing those three main poles may help identify different ways in which they participate in farmers' learning.

As an example, our data suggest that farmers may turn toward peers or scientific inputs in different situations: peers' inputs seem to be mobilized when a solution to a specific, localized problem is needed, whereas scientific inputs seem to be more used as a mean to explain the biological processes underlying an observed phenomenon, thus, enabling the farmer to make generalizations, or to adapt a practice observed in another farmer's system to his own system, since he is able to understand why this practice leads to interesting outcomes.

\section{An analytical framework based on non-ordered and non-obligatory learning steps}

The 5 steps we proposed to describe the learning process (Table 3) are not to be understood as a fixed sequence: they are rather meant as non-ordered and non-obligatory categories of learning mechanisms. Learning can occur without the completion of each one, and our case studies showed examples of farmers going through these steps in different orders, as exemplified in Figure 1.

Explanation of patterns $A$ and $B$ :

$A$ : By performing soil analysis, a farmer realizes that he has a problem of low organic matter content (Mss). Then he hears from a peer that this could be improved through the implementation of cover crops (Gi $n p$ ). 


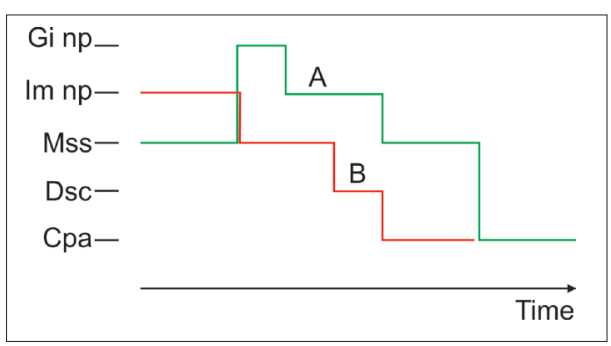

Fig. 1. Two different possible patterns (A, B) of learning mechanism for farmers experienced in conservation agriculture, drawn from our case studies. Explanation for A and B is in the text. Gi np = Get an idea of a new practice; Im $n p=$ Implement a new practice; Mss = Monitoring the state of the system; Dsc = Develop standards of comparison; Cpa $=$ Construct a principle of action .

Consequently, he decides to try this for a couple of years (Im $n p$ ) and the following soil analysis indicates slightly higher organic matter content (Mss). He decides to integrate cover crops in his whole system because he considers this is a solution for him (Cpa).

$B$ : Because of a machine breakdown a farmer is unable to till as usual on a given year $(\operatorname{Im} n p)$. However, he sees that the yields are satisfactory (Mss) and that even though the soil does not look as good as he usually likes to see it, he has less problems of soil erosion this year (Mss). In consequence, he starts rethinking about what makes a soil "good" or not (Dsc), and decides that reduced tillage may be a better opinion for him (Cpa).

\section{Discussion}

A new framework for describing the learning processes

The analytical framework that emerges from our study cases significantly differs from the "classical" view of learning from experience, on a number of aspects: the initiation of the learning process through problem identification, the underlying hypothesis regarding the conscious and deliberate quality of the learning process, the importance given to the construction of standards of comparison, and finally, the leeway left for diversity in the learning processes of farmers.

Initiation of the learning process. Drawing on our results, we would like to emphasize the fact that learning does not necessarily start with the definition of a specific problem or a "warning sign" (CHANTRE, E. et al. 2015): it can also occur either when the farmer wants to try something new in his system, which may be not a response to a problem identified as such, but simply a new practice that seems interesting. We, thus, suggest talking about "Implementing a new practice" rather than "Defining a problem" and "Testing a potential solution". Moreover, as some authors already noted (Lyon, F. 1996; DARnHOFER, I. et al. 2010) learning can occur through chance events as well. Such chance events were often alluded to in our case studies, leading us to distinguish between the planned, opportunistic and fortuitous experiments detailed in the results.

Varied degrees of internationality and consciousness. The fact that a learning process can start with a chance event underlines the idea that not all learning is decided by the learner. The initiation of the process may occur without planning, and other learning steps as well; they may even happen without the awareness of the learner. For instance, our interviews illustrated the fact that "Monitoring the state of the system" may happen on an everyday basis, anytime the farmer goes around the fields, without having necessarily a specific monitoring purpose.

Likewise, constructing a principle of action may be done implicitly by the farmer. Such unconscious learning can be related to the notions of embodied, encultured or embedded knowledge (BLACKLER, F. 1995), but it seems to be quite absent from the classically described learning processes of farmers. We would therefore like to highlight the importance of taking into account unplanned and unconscious cognitive mechanisms as part of the diversity of farmers' learning processes. 
A crucial role for the development of standards of comparison. The idea of developing standards of comparison seemed to be of crucial importance for farmers who had switched to conservation agriculture. It is often considered that monitoring the outcome of an experiment is enough to lead to a decision about the adequacy of the experimented practice, and in fact the development of standards of comparison is not explicitly present in the previous models of farmers' learning.

However, it is important to realize that in order to judge whether or not the practice is adequate, the experimenter needs to know what the outcomes of this practice are, but he also requires some standard or ideal against which the observed outcome is to be judged.

A farmer may acquire information about the outcome of a reduced tillage practice by examining the soil characteristics, but he also need some sort of mental grid of criteria or standards, some idea of what makes a soil "good" or not, to decide if this is a satisfactory outcome. In the case of conservation agriculture, this may be particularly important: the soil starts to be seen as a rich and complex ecosystem rather than an inert substrate; the crops are evaluated not only according to their yield and corresponding profit, but also in relation with their influence on soil structure and composition. We therefore argue that changing the standards of comparison is a major step in learning to practice conservation agriculture.

The framework we presented, thus, differs from the classical models of farmers' learning essentially in the fact that it enables us to account for a large diversity of learning processes, including multifarious starting steps, diverse possible orders of learning mechanisms, and varied degrees of planning and consciousness.

\section{Practical implications}

The implications of this work are mainly related to the improvement of extension ser- vices, farmers' workshops and other types of training.

Clarification and discussion of the standards of comparison used. Given the apparent importance, for farmers who switched to conservation agriculture practices, of developing new standards of comparison, it seems that an explicit clarification of what these standards are would help in improving the impact of training.

Indeed, a farmers' workshop or extension service may lack efficiency if the arguments that are put forward ignore the existing standards. For instance, when the notion of a "beautiful field" implies a soil without any crop residue or small weed, discussing this standard with the farmers may be necessary so that practices such as reduced tillage are not argued against solely because they do not comply with the requirement for "beauty", in some farmers' acceptance of this term.

Roles for science in the learning processes of farmers. Our results show that scientific sources are mobilized by farmers in a diversity of ways: for instance, they can be used to provide ideas of new practices, indicators used by farmers to monitor the state of the system, explanation for a phenomenon observed by farmers, or scientific methodology which may be applied to a certain degree when farmers experiment.

Distinguishing the different roles that scientific information play in farmers' learning processes will help in identifying when to include such information in training, extension services and so on. For instance, as presented in our results, scientific explanation of an observed phenomenon may be especially sought after by farmers who are trying decide whether or not to apply and adapt a successful practice observed somewhere else.

Such hypotheses obviously need to be strengthened through the analysis of a broader sample of farmers, but nonetheless, they highlight the importance of a better understanding of how farmers actually use scientific information, in order so the accuracy of extension services and agricultural training design. 


\section{Conclusion}

Through an in-depth analysis of discourses of farmers experienced in conservation agriculture, we proposed a framework to describe and analyze the learning mechanisms and their articulation over time. The study of a broader sample of farmers across different regions, (which we are currently doing) and complementary qualitative as well as quantitative work should then enable us to identify the more common learning mechanisms processes for farmers experienced in conservation agriculture. This would also enable us to assess potential relationships between the learning mechanisms and the objects of learning, or in other words, potential links between "how farmers learn" and "what farmers learn about". Such an understanding would help highlighting ways in which such learning processes may be fostered, in the case of conservation agriculture, but also potentially for other types of agricultural practices based on the management of ecological processes.

\section{REFERENCES}

Basch, G., Friedrich, T., Kassam, A. and GonzalezSAnchez, E. 2015. Conservation Agriculture in Europe. In Conservation Agriculture. Eds.: FarooQ, M. and Siddique, K.H.M. Springer International Publishing, 357-389.

BLACKLER, F. 1995. Knowledge, knowledge work and organizations: An overview and interpretation. Organization Studies 16. (6): 1021-1046.

Chantre, E. and Cardona, A. 2014. Trajectories of French field crop farmers moving toward sustainable farming practices: change, learning, and links with the advisory services. Agroecology and Sustainable Food Systems 38. (5): 573-602.

Chantre, E., Cerf, M. and Le Bail, M. 2014. A diversity of learning configurations in work situations to reduce the use of agricultural fertilizers and pesticides. Activités 11. (2): on-line. Retrieved from http://activites.revues.org/1061.

Chrétien, F. 2013. Professional transmission in organic farming: how to understand each other and learn at word. Innovations Agronomiques 32. 297-316.

Darnhofer, I., Bellon, S., Dedieu, B. and Milestad, R. 2010. Adaptiveness to enhance the sustainability of farming systems. A review. Agronomy for Sustainable Development 30. (3): 545-555.
De Tourdonnet, S., Brives, H., Denis, M., Omon, B. and Thomas, F. 2013. Accompagner le changement en agriculture: du non labour à l'agriculture de conservation. Agronomie, Environnement et Société 3. (2): 19-27.

Dordas, C. 2015. Nutrient management perspectives in conservation agriculture. In Conservation Agriculture. Eds.: Farooe, M. and Siddique, K.H.M., Springer International Publishing, 79-107.

EIsEnhardT, K.M. 1989. Building theories from case study research. Academy of Management Review 14. (4): 532-550.

FAO 2012. Conservation agriculture. http://www.fao. org/ag/ca/fr/.

Farood, M. and Siddique, K.H.M. 2015. Conservation Agriculture. Springer International Publishing.

Friedrich, T. and Kassam, A.H. 2009. Adoption of conservation agriculture technologies: Constraints and opportunities. Invited paper to the IV World Congress on Conservation Agriculture, 4-7.

Glaser, B.G. and Strauss, A.L. 2009. The discovery of grounded theory: Strategies for qualitative research. Transaction Publishers.

Hobbs, P.R., SAyre, K. and Gupta, R. 2008. The role of conservation agriculture in sustainable agriculture. Philosophical Transactions of the Royal Society B. Biological Sciences 363. (1491): 543-555.

HsieH, H.F. and Shannon, S.E. 2005. Three approaches to qualitative content analysis. Qualitative Health Research 15. (9): 1277-1288.

Ingram, J. 2010. Technical and Social Dimensions of Farmer Learning: An Analysis of the Emergence of Reduced Tillage Systems in England. Journal of Sustainable Agriculture 34. (2): 183-201.

Kilpatrick, S. and Johns, S. 2003. How farmers learn: different approaches to change. The Journal of Agricultural Education and Extension 9. (4): 151-164.

Kolb, D.A. 1984. Experiential learning: Experience as the Source of Learning and Development. Englewood Cliffs, Prentice-Hall, 78-85.

Kummer, S., Milestad, R., Leitgeb, F. and Vogl, C.R. 2012. Building Resilience through Farmers' Experiments in Organic Agriculture: Examples from Eastern Austria. Sustainable Agriculture Research 1. (2): 308-321.

LABARTHE, P. 2009. Services Immatériels et Verrouillage Technologique. Economies et Sociétés 11. 173-196.

LAHMAR, R. 2010. Adoption of conservation agriculture in Europe: lessons of the KASSA project. Land Use Policy 27. (1): 4-10.

Leitgeb, F., Kummer, S., Funes-Monzote, F.R. and VogL, C.R. 2014. Farmers' experiments in Cuba. Renewable Agriculture and Food Systems 29. (1): 48-64.

Lyon, F. 1996. How Farmers Research and Learn: The Case of Arable Farmers of East Anglia, UK. Agriculture and Human Values 13. (4): 39-47.

McGreevy, S.R. 2011. Lost in Translation: Incomer Organic Farmers, Local Knowledge, and the 
Revitalization of Upland Japanese Hamlets. Agriculture and Human Values 29. (3): 393-412.

Millar, J. and Curtis, A. 1997. Moving Farmer Knowledge beyond the Farm Gate: An Australian Study of Farmer Knowledge in Group Learning. European Journal of Agricultural Education and Extension 4. (2): 133-142.

Pittelkow, C.M., Liang, X., Linquist, B.A., van Groenigen, K.J., Lee, J., Lundy, M.E., van Gestel, N., Six, J., Venterea, R.T. and van Kessel, C. 2015. Productivity Limits and Potentials of the Principles of Conservation Agriculture. Nature 517. (7534): 365-368.
Toffolini, Q. 2016. Produire des connaissances actionnables pour la re-conception pas-à-pas de systèmes de culture vers l'agroécologie. PhD Thesis, Paris, AgroParisTech.

Vogl, C.R., Kummer, S., Leitgeb, F., Schunko, C. and Aigner, M. 2015. Keeping the actors in the organic system learning: The role of organic farmers' experiments. Sustainable Agriculture Research 4. (3): 140-148. 